\title{
Prevalence of COVID-19 Among Children and Adolescents While Easing Lockdown Restrictions in Cologne, North Rhine- Westphalia, Germany
}

\author{
Pråvalenz von COVID-19 bei Kindern und Jungendlichen während \\ der Lockerung von Lockdown-Maßnahmen in Köln, Nordrhein- \\ Westfalen, Deutschland
}

Authors

Robert Walter Körner ${ }^{1,}$ 2D, Lutz Thorsten Weber ${ }^{1,2}$

\section{Affiliations}

1 Department of Pediatrics, University Hospital Cologne, Cologne, Germany

2 Faculty of Medicine, University of Cologne, Cologne, Germany

\section{Key words}

COVID-19, SARS-CoV-2, children, adolescents, lockdown, school

\section{Schlüsselwörter}

COVID-19, SARS-CoV-2, Kinder, Jugendliche, Lockdown, Schule

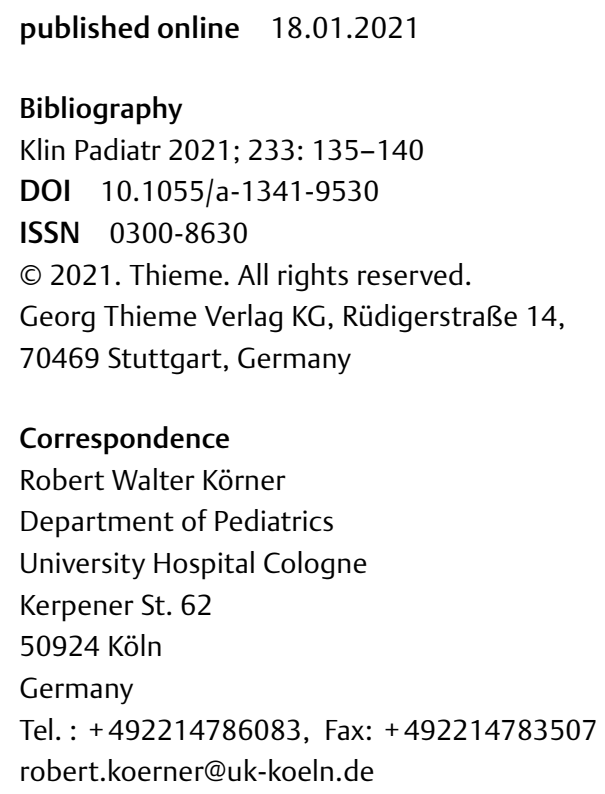

\begin{abstract}
Background In Germany, widespread full closures of schools and day care facilities were part of lockdown measures to control the spread of coronavirus disease 2019 (COVID-19). In the state of North Rhine-Westphalia closures took place on March 16, 2020 and were gradually eased from end of April 2020 until beginning of June 2020 .

Objective This study aims to evaluate the prevalence of COVID-19 among children and adolescents during the reopening period of schools and day care facilities in Cologne, North Rhine-Westphalia, Germany. It further depicts medical history and results of physical examinations of pediatric patients undergoing a test for severe acute respiratory distress syndrome coronavirus 2 (SARS-CoV-2).

Methods Testing for SARS-CoV-2 was carried out by a nasoand / or oropharyngeal swab by local pediatricians at the time of presentation. Samples were analyzed by real-time reverse transcription polymerase chain reaction (RT-PCR). Medical history and physical examination results were retrospectively analyzed.
\end{abstract}

Results 525 children and adolescents presented mainly with mild upper respiratory tract infections. Three patients were diagnosed with COVID-19. Their medical history and examination results did not stand out from the other patients.

Conclusion A precautious stepwise opening of schools and day care facilities was not associated with the occurrence of a relevant prevalence of COVID-19 among children and adolescents. However, a low general prevalence of COVID-19 at the end of the observation period has to be taken into account. Systematic testing might enable adjusted regulations in favor of full closures, especially in the light of increasing evidence for pediatric patients constituting a low-risk group for COVID-19.

\section{ZUSAMMENFASSUNG}

Hintergrund In Deutschland zählt die Schließung von Schulen und Kindertagesstätten zu den Maßnahmen, welche die Ausbreitung von Coronavirus disease 2019 (COVID-19) begrenzen sollen. In Nordrhein-Westfalen fanden die ersten Schließungen am 16. März 2020 statt und wurden von Ende April bis Anfang Juni 2020 schrittweise gelockert. 
Ziel Diese Studie soll einen Einblick in die Prävalenz von COVID-19 bei Kindern und Jugendlichen während der Wiedereröffnungsphase der Schulen und Kindertagesstätten in Köln, NordrheinWestfalen, geben. Weiterhin sollen die Anamnese und die Ergebnisse klinischer Untersuchungen der Patienten erfasst werden, bei denen ein Test auf das severe acute respiratory distress syndrome coronavirus 2 (SARS-CoV-2) vorgenommen wird.

Methoden Die Testung auf SARS-CoV-2 wurde durch einen naso- und / oder oropharyngealen Abstrich durch niedergelassene Kinderärzte vorgenommen. Die Proben wurden mittels real-time reverse transcription polymerase chain reaction (RTPCR) analysiert. Die Anamnese und die Ergebnisse der körperlichen Untersuchungen wurden retrospektiv ausgewertet.

Ergebnis Es wurden 525 Kinder und Jugendliche mit vorwiegend milden Infektionen der oberen Atemwege eingeschlos- sen. Bei drei Patienten wurde COVID-19 diagnostiziert. Ihre Anamnese und die Ergebnisse der körperlichen Untersuchung unterschied sich nicht merklich von den anderen Patienten.

Schlussfolgerung Eine vorsichtige und schrittweise Wiedereröffnung der Schulen und Kindertagesstätten war nicht mit einer relevanten Prävalenz von COVID-19 bei Kindern- und Jugendlichen vergesellschaftet. Allerdings muss berücksichtigt werden, dass zum Zeitpunkt der Untersuchung eine niedrige Gesamtprävelanz in der Bevölkerung vorlag. Eine systematische Testung in Schulen und Kindertagesstätten und spezifische Regulationsmaßnahmen erscheinen gegenüber Vollschließungen vorteilhaft. Dies insbesondere in Anbetracht des niedrigen Risikos für Kinder- und Jugendliche, an COVID-19 schwer zu erkranken.

\section{Introduction}

The coronavirus disease 2019 (COVID-19) pandemic has not only challenged the world's health systems but has also a deep impact on societies and everyday life. In Germany, the first case of an infection with the causative virus severe acute respiratory distress syndrome coronavirus 2 (SARS-CoV-2) was reported on January 27 , 2020 in Munich, Bavaria [15]. By September 10, 2020, over 250.000 cases have been confirmed and more than 9000 people died with COVID-19 in Germany. Only 3.7\% of all infected persons were younger than 10 years and $7.0 \%$ were between 10 and 20 years old. Highest incidences were observed in the elderly people [12].

In Germany, first restrictions to cope with the pandemic were laid down in February, 2020. The restrictions differed somewhat between states. Subsequent lockdown measures in the state of North Rhine-Westphalia comprised also the full closing of schools, kindergartens and day care facilities on March 16, 2020 [10]. At the beginning of the pandemic, it was unknown how much children contribute to the spread of the disease, or if children pose a special risk group. Although first reports showed rather mild courses of COVID-19 in children, uncertainty remained [1,7]. National lockdown measures were eased again on April 20, 2020 [2]. In North Rhine-Westphalia partial opening of schools started on April 23, 2020 for pupils receiving remedial education. On May 11, 2020, a wider opening of schools for even more pupils except elementary school pupils was permitted. Elementary schools were opened on May 25, 2020. School attendance incorporates hygiene regulations and measures to reduce social contact. Kindergartens and day care facilities were reopened on June 8, 2020 under certain precautions; e. $g$. prohibition of taking sick children to the facilities $[9,11]$.

The aim of this work was to evaluate if cases of COVID-19 have increased among children and adolescents after easing lockdown measures including reopening of schools and day care facilities in North Rhine-Westphalia. The studied population was living in Cologne, the state's most populous city. A further aim was to provide insights into medical history, symptoms and physical examination results of children undergoing a test for SARS-CoV-2.

\section{Materials and Methods}

We retrospectively analyzed fully anonymized data which was provided by local primary care pediatricians in Cologne. Data analysis comprised patients' gender, age, test date, test result, reason for testing, medical history including chronic diseases and allergies, as well as results of physical examination. Data was recorded anonymously on the day of presentation by the attending pediatrician. Testing for SARS-CoV-2 was carried out by a naso- and/or oropharyngeal swab. Each patient was tested one time without serial tests or follow-ups. Samples were analyzed by real-time reverse transcription polymerase chain reaction (RT-PCR) and amplification of the E gene of SARS-CoV-2. Samples were assayed in 3 laboratories: Laboratory Dr. Wisplinghoff, Cologne, Germany, Laboratory Dr. Quade \& Colleagues, Cologne, Germany, and Aerztliche Apparategemeinschaft, Duesseldorf, Germany. The laboratories analyzed $81.3,14.9$, and $3.8 \%$ of all samples, respectively. The observation period ranged from April 14, 2020 until June 26, 2020. Inclusion criteria for data analysis were a patient age younger than 18 years and the conduction of a swab test for SARS-CoV-2. Patients older than 18 years of age and patients undergoing different types of testing for an infection with SARS-CoV-2 were excluded. Further, we included daily COVID-19 case numbers of Cologne as published on the city's official website [14]. Data was statistically analyzed by calculation of percentages, mean, median, standard deviation and range using SPSS (Version 25 for MacOS, IBM Corp.).

\section{Results}

- Fig. 1 presents the new daily cases of COVID-19 in the general population of Cologne during and around the study time frame, the number of tests conducted by local pediatricians included in this study, and the opening periods of the different forms of schools and care. Case numbers peaked at the beginning of April and declined thereafter. They continued to decline during the first 2 opening periods and remained relatively stable until the beginning of July. Thus, there was no significant rise in case numbers for 4 weeks after all forms of schools and care had been fully opened. 


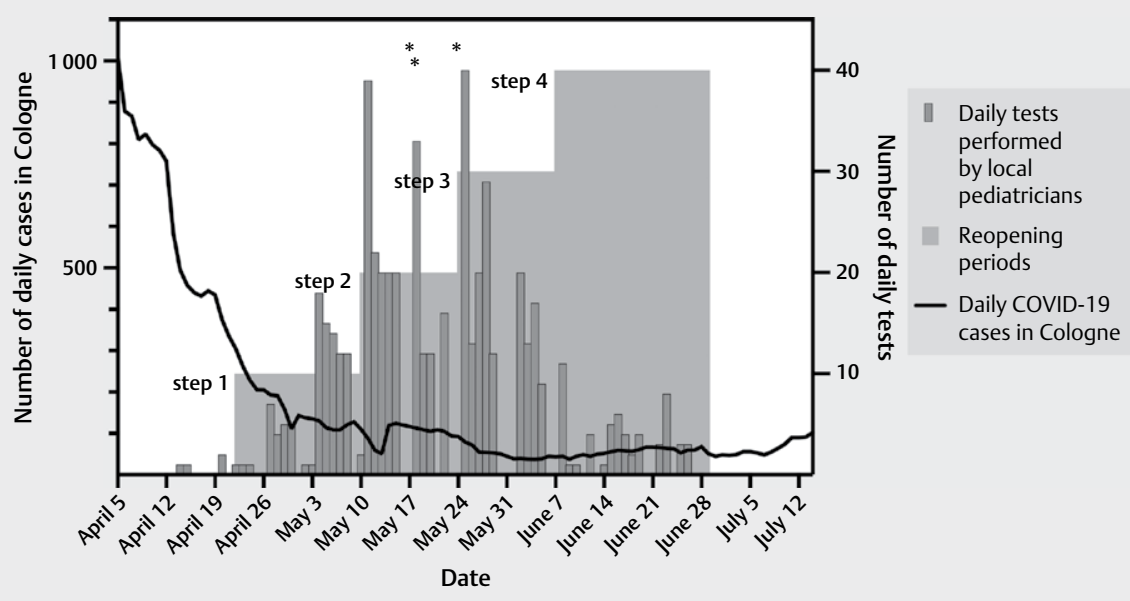

- Fig. 1 The observation period ranged from April 14 until June 26. Date markings represent every sunday. The solid line displays the daily COVID-19 cases in Cologne as published on the city's official website [9]. The bordered, dark grey bars show the amount of tests for SARS-CoV-2 carried out by local pediatricians. The unbordered, light grey bars represent the reopening periods of schools and day care facilities. Step 1 Opening of schools for pupils receiving remedial education. Step 2 Opening of all schools except elementary schools. Step 3 Opening of elementary schools. Step 4 Opening of kindergarten and day care facilities. June 29 marks the beginning of summer vacation. The asterisks depict the onset of symptoms of three patients tested positive for SARS-CoV-2.

- Table 1 Demographics of Study Cohort and SARS-CoV-2 - Test Results.

\begin{tabular}{|l|l|l|}
\hline Gender & abs. & perc. \\
\hline Female & 266 & 50.7 \\
\hline Male & 259 & 49.3 \\
\hline & $\mathrm{n}=525$ & \\
\hline Age & & \\
\hline Mean age; \pm S.D. (years) & $6.1 ; \pm 4.8$ & \\
\hline Median age; range (years) & $4.9 ; 3-17.9$ & \\
\hline Age groups & abs. & perc. \\
\hline $0-2$ years & 142 & 27.0 \\
\hline $2-6$ years & 158 & 30.1 \\
\hline 6-10 years & 116 & 22.1 \\
\hline $10-14$ years & 54 & 10.3 \\
\hline 14-18 years & 55 & 10.5 \\
\hline & $\mathrm{n}=525$ & \\
\hline rRT-PCR for SARS-CoV-2 & abs. & perc. \\
\hline negative & 522 & 99.4 \\
\hline positive & 3 & 0.6 \\
\hline & $\mathrm{n}=525$ & \\
\hline S.D. standard deviation, abs. absolute, perc. percentage.
\end{tabular}

We analyzed 525 cases from 23 local pediatric outpatient departments. As depicted by $>$ Fig. 1 most tests were carried out in the month of May $(72.8 \%)$. Swabs were predominantly taken as combined deep naso- and oropharyngeal swabs (70.9\%). Deep nasopharyngeal swabs and oropharyngeal swabs accounted for 13.9 and $15.2 \%$, respectively. $>$ Table 1 summarizes demographics of the study cohort. The majority of children was younger than 10 years of age and $94.5 \%$ of tests were conducted because children showed symptoms of an infection. Just one test was performed because a child had been exposed to a person who had been sick with
COVID-19. Otherwise, tests were carried out due to impending hospitalization or because a test was demanded by school or kindergarten.

- Table 2 points out an overview of medical history. Most frequent symptoms were as follows: fever (51.2\%), dry cough (31.0\%), sore throat (29.4\%), rhinitis (22.0\%), headache (9.7\%), and abdominal pain $(8.9 \%)$. Almost all children were physically examined (96.6\%). Examination results can be found in > Table 3. Over all, children were in a good general condition (92.1\%). Many patients had an infection of the upper respiratory tract with pharyngitis (42.0\%) and/or rhinitis (23.3\%). Few patients had signs of a lower respiratory tract infection as crackles were present in $2.6 \%$ and signs of bronchial obstruction in $3.6 \%$. Dyspnea was rare $(0.2 \%)$. Some patients had signs of a potential gastrointestinal tract infection with increased peristalsis (6.1\%) and abdominal tenderness (2.4\%).

Only 3 tests $(0.6 \%)$ were positive for SARS-CoV- 2 . All of the affected children were tested because they were sick. The time points of first symptoms are shown in $\mathbf{F i g . 1}$. All three patients were males, had no chronic diseases and presented in a good general condition. None of the patients had knowingly contact to a person who had been tested positive for SARS-CoV-2. The first patient was 4.8 years old. First symptoms occured on May 17 and the SARSCoV-2 test was carried out on May 18. At this time kindergartens and day care facilities were still closed and parents stated that the child was not visiting a child day care. The boy had been ill for one day with abdominal pain. Physical examination was normal. The second patient was 4.5 years old. First symptoms occurred on May 18 and the SARS-CoV-2 test was performed on May 25. It is unknown whether this child visited a special type of day care which was available for families with key workers. As in the first case, regular day care facilities had not yet opened. The patient suffered from fever, sore throat, rhinitis, and dry cough. Physical examina- 
- Table 2 Medical history.

\begin{tabular}{|c|c|c|}
\hline Reason for testing & abs. & perc. \\
\hline Symptoms of infection & 496 & 94.5 \\
\hline Exposure to COVID-19 & 1 & 0.2 \\
\hline \multirow[t]{2}{*}{ Others } & 28 & 5.3 \\
\hline & $n=525$ & \\
\hline Chronic diseases & abs. & perc. \\
\hline Children with chronic diseases & 107 & 20.4 \\
\hline \multicolumn{3}{|l|}{ Specific diseases } \\
\hline - Asthma & 32 & 6.1 \\
\hline - Atopic dermatitis & 12 & 2.3 \\
\hline - ADHD & 2 & 0.4 \\
\hline - Epilepsy & 2 & 0.4 \\
\hline - Diabetes mellitus & 0 & 0.0 \\
\hline \multicolumn{3}{|l|}{ Disease groups } \\
\hline - Allergic diseases & 28 & 5.3 \\
\hline - Neurologic diseases & 23 & 4.4 \\
\hline - Airway diseases & 6 & 1.1 \\
\hline - Heart diseases & 6 & 1.1 \\
\hline - Kidney diseases & 6 & 1.1 \\
\hline - Metabolic diseases & 5 & 1.0 \\
\hline - Gastrointestinal diseases & 4 & 0.8 \\
\hline \multirow[t]{2}{*}{ Others } & 11 & 2.1 \\
\hline & $n=525$ & \\
\hline Allergies & abs. & perc. \\
\hline Children with allergies & 28 & 5.3 \\
\hline Aeroallergens & 21 & 4.0 \\
\hline Food & 5 & 1.0 \\
\hline \multirow[t]{2}{*}{ Others } & 4 & 0.8 \\
\hline & $n=525$ & \\
\hline \multicolumn{3}{|l|}{ Days diseased } \\
\hline Mean; \pm S.D. (days) & $3.2 ; \pm 4.9$ & \\
\hline \multirow[t]{2}{*}{ Median; range (days) } & $2 ; 1-42$ & \\
\hline & $n=496$ & \\
\hline Symptoms & abs. & perc. \\
\hline Fever $\left(>38.0^{\circ} \mathrm{C}\right)$ & 254 & 51.2 \\
\hline Subfebrile $\left(37.5-38.0^{\circ} \mathrm{C}\right)$ & 24 & 4.8 \\
\hline Sore throat & 146 & 29.4 \\
\hline Rhinitis & 109 & 22.0 \\
\hline Headache & 48 & 9.7 \\
\hline Anosmia & 3 & 0.6 \\
\hline Ageusia & 3 & 0.6 \\
\hline Dry cough & 154 & 31.0 \\
\hline Productive cough & 32 & 6.5 \\
\hline Dyspnea & 11 & 2.2 \\
\hline Abdominal pain & 44 & 8.9 \\
\hline Nausea & 22 & 4.4 \\
\hline Vomiting & 32 & 6.5 \\
\hline Diarrhea & 30 & 6.0 \\
\hline Myalgia & 16 & 3.2 \\
\hline \multirow[t]{2}{*}{ Others } & 30 & 6.0 \\
\hline & $n=496$ & \\
\hline
\end{tabular}

- Table 3 Results of physical examination.

\begin{tabular}{|c|c|c|}
\hline & abs. & perc. \\
\hline \multirow[t]{2}{*}{ Examined children } & 507 & 96.6 \\
\hline & $\mathrm{n}=525$ & \\
\hline Good general condition & 467 & 92.1 \\
\hline Reduced general condition & 39 & 7.7 \\
\hline Serious general condition & 1 & 0.2 \\
\hline Rash & 10 & 2.0 \\
\hline Palor & 6 & 1.2 \\
\hline Cyanosis & 0 & 0.0 \\
\hline Pharyngitis & 213 & 42.0 \\
\hline Rhinitis & 118 & 23.3 \\
\hline Nasal congestion & 23 & 4.5 \\
\hline Tonsillitis & 31 & 6.1 \\
\hline Enlargement of cervical lymphnodes & 32 & 6.3 \\
\hline Otitis media & 10 & 2.0 \\
\hline Conjunctivitis & 1 & 0.2 \\
\hline Sinusitis & 1 & 0.2 \\
\hline Dyspnea & 1 & 0.2 \\
\hline Stridor & 1 & 0.2 \\
\hline Wheezing & 18 & 3.6 \\
\hline Coarse crackles & 10 & 2.0 \\
\hline Fine crackles & 3 & 0.6 \\
\hline Diminished breath sound & 0 & 0.0 \\
\hline Abnormal heart sound & 3 & 0.6 \\
\hline Abdominal tenderness & 12 & 2.4 \\
\hline Increased peristalsis & 31 & 6.1 \\
\hline Hepatomegaly & 1 & 0.2 \\
\hline Splenomegaly & 0 & 0.0 \\
\hline \multirow[t]{2}{*}{ Others } & 13 & 2.6 \\
\hline & $n=507$ & \\
\hline
\end{tabular}

abs. absolute, perc. percentage.

tion confirmed rhinitis and pharyngitis and was otherwise unremarkable. The third patient was 16.8 years old and had been sick since May 24. The SARS-CoV-2 test was conducted on May 28. Schools were already open at this time but we have no further information if this boy went to school. Symptoms began with marked bilateral conjunctivitis and were followed by fever and sore throat. Examination revealed pharyngitis and bilateral conjunctivitis without pus.

\section{Discussion}

Despite easing lockdown measures and reopening of schools and day care facilities there was no relevant period prevalence of SARSCoV-2 infections in the studied cohort. Due to the timing of the manifestations in the first 2 cases we can conclude that the reopening of day care facilities did not play a role in the infection of these patients. In the third case schools were already opened at the time the patient became symptomatic. Unfortunately we do not have further information on how the patient might had been infected. Symptoms of positive cases were unspecific and did not stand out from the rest. Children presented with febrile upper airway infec- 
tions to a great extent. In reports on COVID-19 in children clinical characteristics are similar and also frequently consist of fever, cough, sore throat and rhinitis [1,3]. Due to the rather mild clinical course of COVID-19 in children there has been doubt if COVID19 was underdiagnosed in them. Exactly these patients with a mild respiratory tract infection and a good general condition were evaluated in this study. Results suggest that at this moment there is no reason to expect a high frequency of unidentified cases of COVID19 in the studied setting. However, test sensitivity could have been improved since only one swab was conducted at the time of presentation and the point of significant viral replication in upper airways could have been missed.

Anosmia and ageusia may represent symptoms that set COVID19 apart from the common cold. However, they were indicated only by a few patients who eventually were tested negative at time of presentation. It was reported previously, that SARS-CoV-2 may also be detected in fecal samples from children with mild disease up to several weeks [1]. Gastrointestinal symptoms, including abdominal pain, nausea, vomiting, and diarrhea are common in COVID-19 [3]. In the studied cohort less than $10 \%$ presented with gastrointestinal symptoms, but SARS-CoV-2 was not detected in these children. However, no fecal samples were examined.

The reason why children generally develop a milder disease is unknown. Amongst others, a stronger innate immune response in children, less influence of comorbidities, and a different expression of angiotensin converting enzyme 2 (ACE2) receptor have been suggested as possible explanations [7]. Critical and fatal courses in children are possible, but uncommon. In Germany, $85 \%$ of all fatalities occurred in people older than 70 years of age, but only in $0.02 \%$ in people younger than 20 years of age [12]. SARS-CoV-2 is often transmitted to children by household contacts [8]. The role of children during this pandemic was unclear at the beginning and is being discussed controversially.

When schools and day care facilities were closed on March 16, case numbers continued to rise in Cologne and peaked on April 5. Thereafter, case numbers declined and continued to decline despite the first openings of schools on April 23 and on May 11 as can be made out in $>$ Fig. 1. Case numbers remained relatively stable for 4 weeks after all forms of schools and day care had been opened. Thus, the course of daily case numbers in the general population supports the conclusion, that the reopening of schools and day care facilities did not lead to an increase of the COVID-19 prevalence in Cologne.

Meanwhile there is rising evidence that children and adolescents only play a minor role in the spread of SARS-CoV-2 and surveillance data suggests that they do not embody a risk group [12]. On the other hand, prolonged closing of schools and day care facilities bears the risk of impairing scholar and social development. Parents are faced with various problems including academic support, supervision, child care and nutrition. This sets up tensions between them and employers which exerts an economic risk on families. After all, for this particular age group the downsides might outweigh the health-related benefits of school closures. Moreover, provided a low contribution to the spread of SARS-CoV-2, it is uncertain if school closures lead to advantages for the whole society.

In the time from March 1 until July 15 the health department of Cologne detected 23 index cases in schools [5]. There had not been more than one confirmed case at a time at a single school. Moreover, there were 28 pupils who had been exposed to persons with COVID-19. The pupils who had direct contact had no further relevance for school operation because they either had negative SARSCoV-2 test results or they did not visit school while they were ill. The first case of COVID-19 occured on a high school on March 3. In every reported case contact tracing was conducted by the health department of Cologne. Fortunately, there was not a single instance of secondary infections resulting from an index case. The established hygiene and contact measures which among others included small class sizes, staggered break times, and the use of face masks are regarded as beneficial to this result.

A report by the Institute of Labor Economics analyzed the development of case numbers when German schools reopened under strict hygiene and containment measures after the summer vacations [6]. There was no evidence of an aggravating effect of school reopening on case numbers. The reports of the health department of Cologne and the Institute of Labor Economics further strengthen the conclusion that schools employing a hygiene concept do not constitute a catalytic center in the COVID-19 pandemic.

\section{Limitations}

Based on the scarce detection of SARS-CoV-2 in the studied cohort, diagnostic test sensitivity should have been maximized. A limitation is the lack of employing sensitivity-improving means such as serial testing, testing of other samples such as feces and the measurement of antibodies. A small percentage of swabs was taken as oropharyngeal swabs which are known to possess a lower sensitivity than nasopharyngeal swabs [16]. The observation period was set tightly around the reopening phase favoring a fast evaluation. A longer observation period could have delivered more profound results. Further, the study describes the prevalence in a specific location in the given cohort only. Thus, results can be learnt from but cannot be generalized. For example, converse experience was made in Israel where schools had to be shut down shortly after reopening due to several outbreaks in schools by the end of May 2020 [4]. However, reopening in Israel was extensive, rapid, and schools were given little time for preparation [13]. More data from different locations is desirable.

\section{Conclusion}

This study shows that a slow stepwise opening of schools and day care facilities while maintaining hygiene and contact measures was not associated with an increase of the COVID-19 prevalence among children and adolescents in Cologne, Germany. Numerous children have been presented to pediatricians with infections of the upper respiratory tract and it does not seem feasible to identify cases of COVID-19 by medical history or physical examination. That is why a concept for systematic screening and contact tracing, as already implemented by the health department of Cologne, appears to be useful to monitor prevalence of COVID-19 among children and adolescents to enable an adjusted regulation of school and day care facilities in contrast to widespread closures. 


\section{Acknowledgements}

We would like to thank Dr. Wolfgang Breuer, Inga Ditters, Annekatrin Gregor, Dr. Andrea Mertins, Dr. Ania Hoppe, Dr. Irmgard Schmidt, Wolfgang Pollmann, Dr. Stefanie Volz-Neukirch, Dr. Julia Kaiser-Naumann, Dr. Marc Neukirch, Dr. Wei-Shih Liu, Dr. Pervin Seleserpe, Dr. Andrea Wälter, Dr. Fritz Otten, Dr. Elisabeth Lenz, Dr. Ursula Degner, Thomas Vollmert, Dr. Christoph Wilmes, Dr. Markus Treichel, Dr. Anja Holland-Moritz, Dr. Jürgen Krebber, Dr. Liliana Skowron, Dr. Susanne Filfill, Dr. Susanne Reiser-Hartwig, Dr. Ulrike Wolf, Dr. Franziska Platen, Claudia Fliß, Dr. Annette Dohmen, Dr. Öznur H. Ünal-Maelger, Carla Kau, Susanne Fahl, and Dr. Judith Grimme for supplying data and Stefanie Hartmann for data entry.

\section{Contributor's Statement}

LTW and RWK designed the study. RWK carried out data analysis. LTW and RWK drafted, reviewed and revised the initial manuscript.

\section{Conflict of Interest}

The authors declare that they have no conflict of interest.

\section{References}

[1] Cai J, Xu J, Lin D et al. A Case Series of children with 2019 novel coronavirus infection: clinical and epidemiological features. Clin Infect Dis. 2020; Published online: 28 February 2020. doi: 10.1093/cid/ciaa198

[2] Deutsche Bundesregierung. Beschlüsse von Bund und Ländern, April 20, 2020; Available at https://www.bundesregierung.de/breg-de/ themen/coronavirus/bund-laender-corona-1744306. Accessed June 30, 2020

[3] Dong Y, Mo X, Hu Y et al. Epidemiology of COVID-19 Among Children in China. Pediatrics. 2020; 145: e20200702

[4] Estrin D. After Reopening Schools, Israel Orders Them To Shut If COVID-19 Cases Are Discovered.National Public Radio. June 3, 2020. Available at https://www.npr.org/sections/coronavirus-live-updates/2020/06/03/868507524/israel-orders-schools-to-close-whencovid-19-cases-are-discovered. Accessed June 30, 2020.
[5] Gläser-Zorn A, Berkovitch E, Jakobs A et al. COVID-19 an Kölner Schulen. Eine differenzierte Übersicht der Schulentscheidungen im Gesundheitsamt der Stadt Köln bis zum Ende des Schuljahres 2019/2020. Epid Bull 2020; 42: 3-6. DOI: 10.25646/7107

[6] Isphording IE, Lipfert M, Pestel N. School Re-Openings after Summer Breaks in Germany Did Not Increase SARS-CoV-2 Cases. Institute of Labor Economics.October 2020; Available at http://ftp.iza.org/ dp13790. Accessed October 20, 2020.

[7] Lee PI, Hu YL, Chen PY et al. Are children less susceptible to COVID-19? J Microbiol Immunol Infect 2020; 53: 371-372

[8] Lei H, Xu X, Xiao S et al. Household transmission of COVID-19 a systematic review and meta-analysis. J Infect. Epub August 25, 2020; DOI: 10.1016/j.jinf.2020.08.033

[9] Ministerium für Kinder, Familie, Flüchtlinge und Integration des Landes Nordrhein-Westfalen. Schrittweise Öffnung der Kindertagesbetreuungsangebote. Available at https://www.kita.nrw.de/schrittweiseoeffnungder-kindertagesbetreuungsangebote. Accessed June 302020

[10] Ministerium für Schule und Bildung des Landes Nordrhein-Westfalen. Umgang mit dem Corona-Virus an Schulen. 13 March 2020. Available at https://www.schulministerium.nrw.de/docs/bp/Ministerium/ Schulverwaltung/Schulmail/Archiv-2020/200313/index.html. Accessed June 30, 2020.

[11] Ministerium für Schule und Bildung des Landes Nordrhein-Westfalen. Wiederaufnahme des Unterrichts 2020; Available at https://www. schulministerium.nrw.de/docs/Recht/Schulgesundheitsrecht/ Infektionsschutz/300-Coronavirus/index.html. Accessed June 30, 2020

[12] Robert Koch Institute. Coronavirus Disease 2019 (COVID-19) - Daily Situation Report of the Robert Koch Institute - September 10, 2020 Available at https://www.rki.de/DE/Content/InfAZ/N/Neuartiges_ Coronavirus/Situationsberichte/Sept_2020/2020-09-10-en.pdf?_ blob = publicationFile. Accessed September 10, 2020

[13] Sokol S. Israeli schools are reopening, but fears and confusion keep many kids at home. The Times of Israel. May 14 2020; Available at https://www.timesofisrael.com/israeli-schools-reopen-but-fears-andconfusion-keep-many-kids-at-home. Accessed June 30, 2020.

[14] Stadt Köln. Corona-Virus in Köln - Entwicklung der Fallzahlen Available at https://www.stadt-koeln.de/artikel/69443/index.html. Accessed October 20, 2020

[15] Tagesschau. Erster Coronavirus-Fall in Deutschland. 28 January 2020. Available at https://www.tagesschau.de/inland/coronavirusdeutschland-erster-fall-101.html. Accessed June 30, 2020

[16] Wang X, Tan L, Wang X et al. Comparison of nasopharyngeal and oropharyngeal swabs for SARS-CoV-2 detection in 353 patients received tests with both specimens simultaneously. Int J Infect Dis 2020; 94: 107-109 